\title{
Treatment of drooling with sublingual atropine sulfate in children and adolescents with cerebral palsy
}

\author{
Tratamento da sialorreia com sulfato de atropina via sublingual em crianças e \\ adolescentes com paralisia cerebral
}

Bruno L. Scofano Dias', Alexandre R. Fernandes², Heber de S Maia Filho²

\begin{abstract}
Atropine sulfate blocks the muscarinic receptors in the salivary glands and leads to reduced saliva production. There are no published studies about its use in children with cerebral palsy. Objective: To report the effect of sublingual atropine sulfate to treat drooling in children with cerebral palsy by comparing the results of the Drooling Impact Scale in a non-controlled open clinical trial. Results: Twenty-five children were assessed. The difference in the mean scores of the pre- and post-treatment scales reached statistical significance. There was a low frequency of side effects compared to studies with other anticholinergics. Conclusion: The use of sublingual atropine sulfate seems to be safe and there is a reduction in the Drooling Impact Scale score, which suggests efficacy in the treatment of drooling in children and adolescents with cerebral palsy. Our results should be replicated in randomized, placebo-controlled studies with larger numbers of participants.
\end{abstract}

Keywords: cerebral palsy; sialorrhea; child; drug therapy; atropine.

\section{RESUMO}

O sulfato de atropina bloqueia os receptores muscarínicos nas glândulas salivares reduzindo a produção de saliva. Não há estudos publicados relativos ao seu uso para tratamento da sialorreia em crianças com paralisia cerebral. Objetivo: Relatar o efeito do sulfato de atropina sublingual no tratamento da sialorreia em crianças com paralisia cerebral a partir da comparação dos resultados da Drooling Impact Scale em ensaio clínico aberto não controlado. Resultados: Vinte e cinco crianças foram avaliadas. A diferença das pontuações médias nas escalas pré-tratamento e pós-tratamento atingiu significância estatística. Houve baixa frequência de efeitos colaterais em relação a outros anticolinérgicos. Conclusão: O uso de sulfato de atropina sublingual parece ser seguro e está relacionado a uma redução na pontuação da Drooling Impact Scale, o que sugere eficácia no tratamento da sialorreia em crianças com paralisia cerebral. Nossos resultados devem ser replicados em estudos randomizados, placebo controlados, com maior número de participantes.

Palavras-chave: paralisia cerebral; sialorreia; criança; quimioterapia; atropina.

Drooling is the involuntary loss of saliva and buccal content ${ }^{1,2}$ and it usually occurs in infants. Drooling is abnormal in children older than four years and it often persists in children with neurological disorders with neuromuscular incoordination of swallowing, and intelectual disabilities such as cerebral palsy $(\mathrm{CP})^{1}$.

The prevalence of drooling in CP is not often studied ${ }^{1}$. Some authors report a prevalence between $10 \%$ and $58 \%^{3,4,5,6}$. The drooling in CP children is not caused by hypersalivation, but by oral motor dysfunction, dysphagia and/or by an intraoral sensitivity disorder ${ }^{1,5,7,8}$. Drooling affects the lives of CP children and their families, both clinically and socially.
Anterior drooling is the unintentional loss of saliva from the mouth. It may lead to psychosocial consequences for children and for their families such as social isolation, the constant need to remind the individual to swallow the saliva, as well as the need to clean up the excess saliva in the mouth, chin and other areas, and change and wash towels and clothes. There are also physical consequences such as perioral infections and damages to the dentition ${ }^{1,6,8}$. Posterior drooling occurs whenever the saliva slips from the tongue to the pharynx. It poses a saliva aspiration risk, which may not be diagnosed before the development of significant lung injury ${ }^{1,6}$.

${ }^{1}$ Rede SARAH de Hospitais de Reabilitação; Rio de Janeiro RJ, Brasil.

${ }^{2} U$ niversidade Federal Fluminense; Niterói RJ, Brasil.

Correspondence: Bruno L. Scofano Dias; Avenida Vice Presidente José Alencar, 1455 / bloco 5 / apartamento 104; 22775 -033 Rio de Janeiro RJ, Brasil. E-mail: brunoscofano91@gmail.com

Conflict of interest: There is no conflict of interest to declare.

Received 12 August 2016; Received in final form 23 November 2016; Accepted 20 December 2016. 
The drooling severity and impact may be assessed through objective or subjective methods 9 . The objective methods include the measurement of the salivary flow and the direct observation of the loss of saliva; however, these are complicated and/or invasive methods. Subjective scales are useful and appropriate methods to measure changes in drooling, assessing the impact on families, caregivers and on the individuals themselves ${ }^{9,10}$.

Some drooling treatment modalities can be used in CP such as training for sensory awareness and oral motor skills; oral, transdermal and sublingual anticholinergic drugs; application of botulinum toxin; and surgical management ${ }^{8,11,12,13}$. Glycopyrrolate, benztropine, scopolamine and trihexyphenidyl are the most-used systemic anticholinergic drugs. They induce a significant reduction in saliva flow and their effectiveness has been confirmed in several studies ${ }^{14,15,16,17,18,19}$. On the other hand, they can lead to side effects such as vomiting, diarrhea, irritability, mood changes and insomnia.

Although atropine sulfate was acknowledged as effective many years ago, it never received wide acceptance in the treatment of chronic drooling. Its mechanism of action is by blocking the muscarinic receptors (M3) in the salivary glands, leading to reduced saliva production ${ }^{17}$. Some articles have reported its use in the treatment of drug-induced drooling $^{20,21,22}$ and in Parkinson's disease patients ${ }^{23}$. The only article referring to its use in treating drooling in children or adolescents reported the case of a successfully-treated 14-year-old boy with metachromatic leukodystrophy ${ }^{17}$. There is only one prospective, randomized, placebo-controlled double-blind study that has investigated the use of sublingual atropine sulfate to treat drooling. The cohort comprised 22 adult subjects with upper gastrointestinal tract cancer and the atropine had no effect on those patients in comparison to the placebo ${ }^{24}$.

There is no published study assessing the use of atropine sulfate to treat drooling in CP children.

The aim of the current study was to report the effect of using sublingual atropine sulfate to treat drooling in $\mathrm{CP}$ children and adolescents by comparing the results of the Drooling Impact Scale (DIS). Our hypothesis was that there would be a reduction in the DIS score after the use of atropine sulfate, as well as few side effects.

\section{METHODS}

\section{Participants}

All children and adolescents treated at a neurorehabilitation center in Rio de Janeiro (Brazil) were assessed for eligibility. The inclusion criteria were: 1) CP diagnosis according to the International Executive Committee for the Definition of Cerebral Palsy ${ }^{25}$; 2) presence of drooling as defined by Blasco $^{2}$; 3) presence of clinical and/or social damage for the children, followed or not by the feeling in the family of overload caused by drooling; 4) ages between two and 17 years; 5) weight greater than or equal to $10 \mathrm{~kg}$; and 6) normal electrocardiogram. The following criteria were interpreted as losses: 1) presence of side effects; 2) irregular use of atropine sulfate; 3) discontinuation in the use of atropine sulfate.

Thirty-three patients met the inclusion criteria. Eight individuals met the loss criteria, one due to irregular use of atropine sulfate, three due to discontinuation in the use of atropine sulfate, and four due to side effects. The final sample comprised 25 patients. Table 1 shows the participants' sociodemographic and clinical characteristics.

\section{Ethics}

The current study was approved by the Research Ethics Committee of the SARAH Network of Rehabilitation Hospitals (Certificate of Submission for Ethics Assessment 48300015.0.0000.0022). The informed consent form was signed by the patients and their caregivers.

\section{Data collection}

The data were collected by five pediatricians (including the author) of the neurorehabilitation center, who were trained to homogeneously perform the task and were also responsible for prescribing the atropine sulfate. The following sociodemographic and clinical variables were analyzed in addition to the results of the DIS: age, gender, weight, and the Gross Motor Function Classification System ${ }^{26}$. The following comorbidities were taken into consideration: 1) dysphagia was defined as the presence of oral (difficulty in receiving food bolus, extraoral loss of food, suction disorder, increased oral transit time, food residue) and/or pharyngeal phase symptoms (tachypnea and/or dyspnea, coughing and/or gagging, throat clearing, nasal regurgitation during or immediately after feeding); 2) gastroesophageal reflux disease (GERD) defined as the presence of vomiting, regurgitation, nausea, refusal of solid food, belching and hiccups during or immediately after feeding; and 3) intellectual disability

Table 1. Patient characteristics ( $n=25)$.

\begin{tabular}{lc}
\hline Gender (male / female) & $13 / 12$ \\
\hline Mean age (year) \pm SD & $8.6 \pm 4.2$ \\
Mean weight (Kg) / Minimum - Maximum (Kg) & $19.5 / 10.9-37.5$ \\
GMFCS, n (\%) & \\
\hline I & Zero (zero) \\
II & $2(8)$ \\
III & $1(4)$ \\
IV & $7(28)$ \\
V & $15(60)$ \\
Comorbidities, n (\%) & \\
\hline Dysphagia & $15(60)$ \\
GERD & $13(52)$ \\
ID & $24(96)$ \\
\hline Epilepsy & $17(68)$ \\
\hline
\end{tabular}

SD: standard deviation; GMFCS: gross motor function classification system; GERD: gastroesophageal reflux disease; ID: intellectual disability. 
as defined by the criteria of the Diagnostic and Statistical Manual of Mental Disorders $V^{27}$, and epilepsy as defined by the criteria of the International League Against Epilepsy ${ }^{28}$.

\section{The Drooling Impact Scale}

The current study used a Portuguese translated, but not validated in Brazil, version of the DIS (its use was permitted by the author of the original scale). Although not yet validated, the version of the scale translated into Portuguese had already been used in clinical practice for several months in our hospital and, in our evaluation, the families easily understood each question. The DIS has been specifically designed to quantify and longitudinally assess the short/medium-term benefits of interventions for drooling and changes in the impact caused by drooling, on children with neurodevelopmental disorders, including $\mathrm{CP}$ and intellectual disabilities, and on their caregivers. The items comprising the scale (described in the Table 2) are constructed as a 10-point scale. The DIS can be answered by the caregiver or by the patient, and it may be also annotated by the interviewer ${ }^{11}$.

\section{Atropine sulfate}

There are no specific atropine sulfate formulations for sublingual use; thus, ophthalmic drops of $0.5 \%$ were used. The prescribed dose consisted of one sublingual drop administered three times a day at six-hour intervals for patients weighing between $10 \mathrm{~kg}$ and $19 \mathrm{~kg}$ and two sublingual drops administered three times a day at six-hour intervals for patients with a weight equal to or greater than $20 \mathrm{~kg}$. These doses were determined from the single article on the use of atropine sulfate to treat drooling in an adolescent, in which there was a good tolerability level ${ }^{17}$.

There are no specific studies on the bioavailability of $0.5 \%$ sublingual atropine sulfate drops. Rajpal et al. published a study in which a preparation of $2 \%$ atropine sulfate was formulated (a concentration four times greater than that employed by us) and administered by sublingual injection, not by drops, to adult individuals. All the volunteers showed

Table 2. Drooling impact scale items.

1- How frequently did your child dribble?
2- How severe was the drooling?
3- How many times a day did you have to change bibs or clothing
due to drooling?
4- How offensive was the smell of the saliva on your child?
5- How much skin irritation has your child had due to drooling?
6- How frequently did your child's mouth need wiping?
7- How embarrassed did your child seem to be about
his/her dribbling?
8- How much do you have to wipe or clean saliva from household
items, e.g. toys, furniture, computers?
9- To what extent did your child's drooling affect his or her life?
10- To what extent did your child's drooling affect you and your
family's life?

early symptoms of atropinization, such as dry mouth, blurring vision, and thirst, 15 to 30 minutes after the injection ${ }^{29}$.

\section{Study design and interventions}

This was a non-controlled open clinical trial conducted between July 2013 and June 2014. All patients who met the inclusion criteria were evaluated on the DIS before the beginning of the treatment. The patients started using $0.5 \%$ sublingual atropine sulfate and returned after 30 days of effective use of the substance. Patients who met the loss criteria were excluded from the study. The remaining patients were included in the final sample and evaluated on the DIS again.

\section{Statistical analysis}

The SPSS software version 20 (IBM Corp.) was used for statistical analysis. Descriptive statistics were used to analyze the sociodemographic and clinical variables. For the analytical statistics, the Kolmogorov-Smirnov test and graphical analyses were applied to the pre- and post-treatment DIS samples and both showed normal distribution. The pre- and post-treatment DIS scores were considered as continuous variables and the samples were considered as paired because the same sample was evaluated before and after the atropine sulfate treatment. Thus, the paired t-test was used in the following analyses: 1) comparison between the total pre- and post-treatment DIS scores; 2) analysis of the total scores for each pre- and post-treatment DIS question; 3) comparison between the means of intervening variables in "Yes" (presence) and "No" (absence) samples of each comorbidity in relation to the pre-treatment DIS score (considered as a drooling severity marker) and the difference between the mean pre- and post-treatment DIS scores (considered as improvement the level marker related to the use of atropine sulfate). The significance level of $95 \%(p<0.05)$ was adopted in all analyses.

\section{RESULTS}

\section{Comparison between the total pre- and post-treatment DIS scores}

Table 3 shows the reduction in the mean pre- and post-treatment DIS scores. The difference between these means reached statistical significance $(\mathrm{p}<0.0001)$.

Table 3. Comparison between the total pre- and post-treatment DIS scores. $n=25$.

\begin{tabular}{|c|c|c|c|c|c|}
\hline Variables & Minimum & Maximum & Mean & SD & $p$-value \\
\hline DIS pre & 25 & 86 & 61.80 & 13.92 & \\
\hline DIS post & 12 & 61 & 25.60 & 11.37 & \\
\hline $\begin{array}{l}\text { Difference DIS } \\
\text { pre-DIS post }\end{array}$ & 6 & 60 & 36.20 & 16.59 & $<0.0001$ \\
\hline
\end{tabular}

SD: standard deviation; DIS: drooling impact scale; DIS pre: pre-treatment DIS; DIS post: post-treatment DIS. 


\section{Analysis of the total scores of each pre- and post-treatment DIS question}

The analysis of the difference between the mean score of each pre- and post-treatment DIS question is summarized in Table 4. It shows a statistically significant reduction in all questions ( $\mathrm{p}<0.0001$ in questions $1,2,3,6,8,9$ and 10; $\mathrm{p}<0.003$ in question 4), except in questions 5 and 7.

\section{Comparison between the means of intervening variables}

In Table 5, the absence of GERD was correlated with the greater difference between the mean scores in the preand post-treatment DIS. It reached statistical significance

Table 4. Analysis of the total scores of each pre- and post-treatment DIS question.

\begin{tabular}{lccc|}
\hline Difference (DIS pre - DIS post) & Mean & SD & p-value \\
\hline 1- Drooling frequency & 4.68 & 2.268 & $<0.0001$ \\
\hline 2- Drooling severity & 4.32 & 2.212 & $<0.0001$ \\
\hline 3- Frequency of bibs or clothing changes & 36.80 & 25.45 & $<0.0001$ \\
\hline 4- Saliva's smell offensiveness & 1.80 & 2.708 & $<0.003$ \\
\hline 5- Skin irritation & 0.20 & 0.577 & 0.96 \\
\hline 6- Frequency of mouth wiping & 5.32 & $2.545<0.0001$ \\
\hline 7- Embarrassment caused by drooling & 1.44 & 25.99 & 0.11 \\
\hline $\begin{array}{l}\text { 8- Frequency of wiping saliva from } \\
\text { household items }\end{array}$ & 42.40 & 29.48 & $<0.0001$ \\
\hline 9- Impact of drooling in child's life & 49.60 & 30.48 & $<0.0001$ \\
\hline 10- Impact of drooling in family's life & 55.60 & $30.29<0.0001$ \\
\hline
\end{tabular}

DIS: drooling impact scale; SD: standard deviation; DIS pre: pre-treatment DIS; DIS post: post-treatment DIS.

Table 5. Comparison between the means of intervening variables.

\begin{tabular}{|c|c|c|c|c|}
\hline \multirow{2}{*}{ Variable } & \multicolumn{2}{|c|}{ DIS pre } & \multicolumn{2}{|c|}{$\begin{array}{l}\text { Difference DIS } \\
\text { pre - DIS post }\end{array}$} \\
\hline & Mean & $\mathrm{p}$-value & Mean & $p$-value \\
\hline \multicolumn{5}{|c|}{ Dysphagia } \\
\hline Yes & 59.47 & \multirow{2}{*}{0.649} & 32.33 & \multirow{2}{*}{0.158} \\
\hline No & 66.75 & & 42 & \\
\hline \multicolumn{5}{|l|}{ GERD } \\
\hline Yes & 58.85 & \multirow{2}{*}{0.279} & 29.15 & \multirow{2}{*}{0.024} \\
\hline No & 65 & & 43.83 & \\
\hline \multicolumn{5}{|l|}{ ID } \\
\hline Yes & 61.5 & \multirow{2}{*}{ - } & 35.63 & \multirow{2}{*}{ - } \\
\hline No & 69 & & 50 & \\
\hline \multicolumn{5}{|l|}{ Epilepsy } \\
\hline Yes & 59.47 & \multirow{2}{*}{0.23} & 35.63 & \multirow{2}{*}{0.02} \\
\hline No & 66.75 & & 47.13 & \\
\hline
\end{tabular}

DIS: drooling impact scale; DIS pre: pre-treatment; DIS post: post-treatment; GERD: gastroesophageal reflux disease; ID: intellectual disability
( $p<0.024)$ and so did the absence of epilepsy $(\mathrm{p}<0.02)$. In other words, the samples from patients without GERD and epilepsy reached statistically significant improvement levels due to the use of atropine sulfate. The absence or presence of any of the comorbidities did not influence the drooling severity since no statistically significant results were found separately in the mean pre-treatment DIS scores for any absence or presence of any of the studied comorbidities.

\section{Side effects}

Side effects were found in four out of the 33 patients who started the study $(12,1 \%)$ and their respective frequency occurred as follows: fever and flush (1); irritability (1); flush and irritability (1); flush and angioedema (1).

\section{DISCUSSION}

To our knowledge, this is the first study that reports the use of sublingual atropine sulfate to treat drooling in $\mathrm{CP}$ children and adolescents.

The indication of any type of drooling treatment in $\mathrm{CP}$ patients must take into account their social and family contexts. Thus, one should indicate efficient and more specific methods that cause less overload to each patient/family. The efficacy of some of the available treatment modalities have been proven; however, they have features that hinder the patients' access to these techniques. The oral, transdermal, or sublingual use of anticholinergic drugs has the advantage of not requiring medical and nursing apparatus, specific equipment, sedation or anesthesia in order to be applied.

The atropine sulfate was chosen in the current study due to its originality in the treatment of drooling in $\mathrm{CP}$ patients and to the easy access to the drug. However, one disadvantage is its transient effect and, consequently, the need for its continuous use of three doses a day in order to maintain its effect.

Atropine sulfate use was associated with a statistically significant reduction in the DIS score $(\mathrm{p}<0.0001)$ in this $\mathrm{CP}$ population. Other studies have demonstrated the benefit of other anticholinergic drugs; however, the current study achieved a better safety profile ( $12.1 \%$ of the patients reported side effects). Mier et al. ${ }^{15}$ showed that glycopyrrolate effectively controlled the CP patients' drooling; however, $20 \%$ of the children had side effects severe enough to discontinue the use of the drug. Zeller et al..$^{19}$ reached percentages of response to oral glycopyrrolate with a peak of $56.7 \%$ in the $16^{\text {th }}$ week. They found several side effects in $20.4 \%$ of the patients. Mato Montero et al. ${ }^{16}$ found significant drooling reduction $(\mathrm{p}<0.005)$ in a transdermal scopolamine group in comparison to a placebo group, in which $13.3 \%$ of patients were excluded from the study due to severe side effects. Camp-Bruno et al. ${ }^{14}$ found a significant drooling decrease in their benztropine group in comparison to the placebo group, but severe cholinergic side effects required the discontinuation of the drug 
in $12 \%$ of the patients. Carranza-del Rio et al. ${ }^{18}$ concluded that most of their dystonia CP patients (96\%) reported some improvement in involuntary movements and/or drooling; however, $69.3 \%$ of them showed side effects. Among the several anticholinergic drugs, sublingual atropine sulfate seems to have a more local and lesser systemic effect. This feature may have contributed to a better safety profile.

The DIS questions assess ten different drooling-influence parameters in the lives of the children and their families. The current study individually analyzed the effect of atropine sulfate on each parameter by analyzing the difference between the means of each question in the pre- and post-treatment DIS. This analysis showed statistically significant reduction in all questions, except in questions 5 and 7 . Question 5 relates to skin irritation, and its frequency was low among the patients in the sample. Question 7 concerns how embarrassed the patient feels due to drooling; this feeling was reduced by the presence of intellectual disability, which had a high incidence in the sample. Both situations led to low pre-treatment DIS scores in these questions and, consequently, to a statistically significant reduction in the improvement potential.

The fact that only the samples from patients with no GERD and epilepsy achieved statistically significant improvement levels due to the use of atropine sulfate could be related to the clinical perception that the presence of GERD (which stimulates the parasympathetic route and saliva production) and epilepsy (due to the need to use certain anticonvulsants) could increase drooling severity and reduce the therapeutic response to atropine. However, we did not come to the same conclusion as we did not find statistically significant results in the mean pre-treatment DIS scores (drooling severity marker) for any absence or presence sample of any of our studied comorbidities.

The use of sublingual atropine sulfate seems to be safe and is related to a reduction in DIS scores, which suggests efficacy in the treatment of drooling in CP children and adolescents. However, since it is a non-placebo-controlled open clinical trial, our results must be interpreted with parsimony and replicated in randomized, placebo-controlled studies with larger numbers of participants.

\section{Acknowledgments}

The authors thank Dr. Susan M. Reid for allowing us using the Drooling Impact Scale, Dr. Fernanda Marinho de Lima, Dr. Fernanda Jordão Pinto Marques, Dr. Marta Cristina da Silva Teixeira, Dr. Rafael Rodrigues Barra for helping in the data collection and the children and their families for participating in the study.

\section{References}

1. Reddihough D, Erasmus CE, Johnson H, Mckellar GM, Jongerius $\mathrm{PH}$. Botulinum toxin assessment, intervention and aftercare for paediatric and adult drooling: international consensus statement. Eur J Neurol. 2010;17(Suppl 2):109-21. https://doi.org/10.1111/j.1468-1331.2010.03131.x

2. Blasco PA. Surgical management of drooling. Dev Med Child Neurol. 1992;34(4):368-9. https://doi.org/10.1111/j.1469-8749.1992.tb11444.x

3. Ekedahl C, Månsson I, Sandberg N. Swallowing dysfunction in the brain-damaged with drooling. Acta Otolaryngol. 1974;78(1-2):141-9. https://doi.org/10.3109/00016487409126339

4. Van De Heyning P, Marquet JF, Creten WL. Drooling in children with cerebral palsy. Acta Otorhinolaryngol Belg. 1980;34(6):691-705.

5. Tahmassebi JF, Curzon MEJ. The cause of drooling in children with cerebral palsy - hypersalivation or swallowing defect? Int J Paediatr Dent. 2003;13(2):106-11. https://doi.org/10.1046/j.1365-263X.2003.00439.x

6. Erasmus CE, van Hulst K, Rotteveel JJ, Willemsen MA, Jongerius PH. Clinical practice: swallowing problems in cerebral palsy. Eur J Pediatr. 2012;171(3):409-14. https://doi.org/10.1007/s00431-011-1570-y

7. Erasmus CE, Van Hulst K, Rotteveel LJ, Jongerius PH, Van Den Hoogen FJ, Roeleveld N et al. Drooling in cerebral palsy: hypersalivation or dysfunctional oral motor control? Dev Med Child Neurol. 2009;51(6):454-9. https://doi.org/10.1111/j.1469-8749.2008.03243.x

8. Senner JE, Logemann J, Zecker S, Gaebler-Spira D. Drooling, saliva production, and swallowing in cerebral palsy. Dev Med Child Neurol. 2004:46(12):801-6. https://doi.org/10.1111/j.1469-8749.2004.tb00444.x

9. Reid SM, Johnson HM, Reddihough DS. The Drooling Impact Scale: a measure of the impact of drooling in children with developmental disabilities. Dev Med Child Neurol. 2010;52(2):e23-8. https://doi.org/10.1111/j.1469-8749.2009.03519.x
10. Jongerius PH, LimbeekJ, Rotteveel JJ. Assessment of salivary flow rate: biologic-variation and measure error. Laryngoscope. 2004;114(10):1801-4. https://doi.org/10.1097/00005537-200410000-00023

11. Reddihough DS, Johnson $\mathrm{H}$. Assessment and management of saliva control problems in children and adults with neurological impairment. J Dev Phys Disabil. 1999;11(1):17-24. https://doi.org/10.1023/A:1021804500520

12. Little SA, Kubba H, Hussain SS. An evidence-based approach to the child who drools saliva. Clin Otolaryngol. 2009;34(3):236-9. https://doi.org/10.1111/j.1749-4486.2009.01917.x

13. Hornibrook J, Cochrane N. Contemporary surgical management of severe sialorrhea in children. ISRN Pediatr. 2012;2012:364875. https://doi.org/10.5402/2012/364875

14. Camp-Bruno JA, Winsberg BG, Green-Parsons AR, Abrams JP. Efficacy of benztropine therapy for drooling. Dev Med Child Neurol. 1989;31(3):309-19. https://doi.org/10.1111/j.1469-8749.1989.tb04000.x

15. Mier RJ, Bachrach SJ, Lakin RC, Barker T, Childs J, Moran M Treatment of sialorrhea with glycopyrrolate: a double-blind, dose-ranging study. Arch Pediatr Adolesc Med. 2000;154(12):1214-8. https://doi.org/10.1001/archpedi.154.12.1214

16. Mato Montero A, Limeres Posse J, Tomás Carmona I, Fernández Feijoo J, Diz Dios P. Control of drooling using transdermal scopolamine skin patches: a case report. Med Oral Patol Oral Cir Bucal. 2008;13(1):E27-30.

17. Rapoport A. Sublingual atropine drops for the treatment of pediatric sialorrhea. J Pain Symptom Manage. 2010;40(5):783-8. https://doi.org/10.1016/j.jpainsymman.2010.02.007

18. Carranza-del Rio J, Clegg NJ, Moore A, Delgado MR. Use of trihexyphenidyl in children with cerebral palsy. Pediatr Neurol. 2011;44(3):202-6. https://doi.org/10.1016/j.pediatrneurol.2010.09.008 
19. Zeller RS, Davidson J, Lee HM, Cavanaugh PF. Safety and efficacy of glycopyrrolate oral solution for management of pathologic drooling in pediatric patients with cerebral palsy and other neurologic conditions. Ther Clin Risk Manag. 2012;8:25-32. https://doi.org/10.2147/TCRM.S27362

20. Freudenreich O. Drug-induced sialorrhea. Drugs Today (Barc). 2005;41(6):411-8. https://doi.org/10.1358/dot.2005.41.6.893628

21. Sockalingam S, Shammi C, Remington G. Clozapine-induced hypersalivation: a review of treatment strategies. Can J Psychiatry. 2007;52(6):377-84.

22. Mustafa FA, Khan A, Burke J, Cox M, Sherif S. Sublingual atropine for the treatment of severe and hyoscine-resistant clozapine-induced sialorrhea. Afr J Psychiatry (Johannesbg). 2013;16(4):242. https://doi.org/10.1177/070674370705200607

23. Hyson HC, Johnson AM, Jog MS. Sublingual atropine for sialorrhea secondary to parkinsonism: a pilot study. Mov Disord. 2002;17(6):1318-20. https://doi.org/10.1002/mds.10276

24. De Simone GG, Eisenchlas JH, Junin M, Pereyra F, Brizuela R. Atropine drops for drooling: a randomized controlled trial. Palliat Med. 2006;20(7):665-71. https://doi.org/10.1177/0269216306071702
25. Rosenbaum P, Paneth N, Leviton A, Goldstein M, Bax M, Damiano D et al. A report: the definition and classification of cerebral palsy: April 2016. Dev Med Child Neurol. 2007;109(Suppl):8-14.

26. CanChild Center for Childhood Disability Research. Institute for Applied Health Sciences. GMFCS - E \& R: Sistema de classificação de função motora grossa: ampliado e revisto. Hamilton: CanChild Center for Childhood Disability Research; 2007 [cited 2015 Oct 17]. Available from: https:// www.canchild.ca/system/tenon/assets/attachments/000/000/075/ original/GMFCS-ER_Translation-Portuguese2.pdf

27. Cordioli VA, Kieling C, da Silva BTC, Passos IC, Barcellos MT. Deficiências intelectuais. In: Cordioli VA, Kieling C, Silva BTC, Passos IC, Barcellos MT, editores. Referência rápida aos critérios diagnósticos do DSM-5. Porto Alegre: Artmed; 2014. p. 17-23.

28. Fisher RS, Acevedo C, Arzimanoglou A, Bogacz A, Cross H, Elger CE et al. A practical clinical definition of epilepsy. Epilepsia. 2014;55(4):475-82. https://doi.org/10.1111/epi.12550

29. Rajpal S, Ali R, Bhatnagar A, Bhandari SK, Mittal G. Clinical and bioavailability studies of sublingually administered atropine sulfate. Am J Emerg Med. 2010;28(2):143-50. https://doi.org/10.1016/j.ajem.2008.10.025 